\title{
NOVEDADES LEGISLATIVAS \\ AÑO 2009
}

\section{Ley para el Fomento y Desarrollo de la Competitividad de la Micro, Pequeña y Mediana Empresa.}

Decreto \#135-2008

Gaceta \#31,811 del 14 de enero 2009

2. Ley Especial que regula el Plebiscito y el Referendo.

Decreto \#135-2009

Gaceta \#31,972 del 27 de julio 2009

3. Ley sobre Actividades Nucleares y Seguridad Radiológica.

Decreto \#195-2009

Gaceta \#32,063 del 14 de noviembre 2009

\section{Ley General de Aguas.}

Decreto \#181-2009

Gaceta \#32,088 del 14 de diciembre 2009

\section{Ley de Fomento y Protección del Parque Nacional Montaña} de Celaque, Procelaque.

Decreto \#57-2009

Gaceta \#32,098; 26 de diciembre 2009

\section{Ley del Sistema Nacional de Gestión del Riegos. (SINAGER).}

Decreto \#151-2009

Gaceta \#32,098 del 26 de diciembre 2009

\section{Ley Especial de Educación y Comunicación Ambiental.}

Decreto \#158-2009

Gaceta \#32,099 del 28 de diciembre 2009 